\title{
Use of a Refined Corporate Social Responsibility Model to Mitigate Information Asymmetry and Evaluate Performance
}

\author{
Ya-Lan Wang ${ }^{1}$, Kao-Yi Shen ${ }^{2, *}$, Jim-Yuh Huang ${ }^{3}$ and Pin Luarn ${ }^{1}$ \\ 1 Graduate School of Management, National Taiwan University of Science and Technology, Taipei 10607, \\ Taiwan; d10216006@mail.ntust.edu.tw (Y.-L.W.); luarn@mail.ntust.edu.tw (P.L.) \\ 2 Department of Banking \& Finance, Chinese Culture University, Taipei 11114, Taiwan \\ 3 IEMBA, College of Business, National Taipei University, New Taipei City 23741, Taiwan; \\ jimhuang@gm.ntpu.edu.tw \\ * Correspondence: kyshen@sce.pccu.edu.tw
}

Received: 17 July 2020; Accepted: 11 August 2020; Published: 12 August 2020

\begin{abstract}
While the importance of Corporate Sociable Responsibility (CSR) has been widely acknowledged, research on how to guide a company in evaluating and improving its CSR performance is relatively under-explored. This paper adopts the predominant framework from the United Nations $(\mathrm{UN})$ and proposes a refined CSR model by using a hybrid multiple criteria decision-making (MCDM) approach. The proposed approach is expected to mitigate the potential information asymmetry issue that might deteriorate the CSR performance of a company. To illustrate the hybrid approach, this study analyzes the CSR performance of four publicly listed information technology (IT) manufacturing companies with the participation of senior domain experts, by using the proposed approach. The CSR performance ranking results are consistent by using various experiments, which is similar to the annual CSR contest held by a prominent organization from Taiwan in 2019. In addition, we illustrate how to apply this refined model to gain managerial insights and pursue sustainable CSR improvement with a priority.
\end{abstract}

Keywords: multiple criteria decision-making (MCDM); decision-making trial and evaluation laboratory (DEMATEL); DEMATEL-based ANP (DANP); fuzzy assessment; corporate social responsibility (CSR); corporate governance; sustainable development

\section{Introduction}

In recent years, Corporate Social Responsibility (CSR) has gained increasing awareness among global investors. Its importance is not confined to the general requirement of a company to increase its shareholders' value, but rather extends to covering the interests of broader stakeholders. To capture the essence of CSR, the Triple Bottom Line (TBL), proposed by Elkington [1], would be an adequate entry point. The TBL raises a triple challenge to the economic prosperity, environmental quality, and social equity of contemporary businesses. A decent corporate should confront and tackle the problems in the three aspects.

Aside from making profits, corporations are also responsible for non-financial aspects, such as environment protection, social welfare, corporate governance, employee care, product liability, and so on [2]. Since CSR encourages corporations to address multiple aspects, it has triggered a debate on how to model and assess the performance of a corporate on fulfilling CSR. For instance, Carroll and Buchholtz [3] suggested the framework of a four-layer CSR pyramid over time. Some other researchers, such as Costa and Menichini [4] have applied a balanced scorecard (BSC) approach that involves various indicators. Nowadays, the United Nations (UN) has concluded three categories 
(i.e., environment, social, and governance issues) as a universal framework that highlights the three aspects' progress of those large companies and listed stocks in many countries. Its global impact is profound.

According to an article published in the Harvard Law School Forum, 78\% of S \& P 500 corporations issued a sustainability report in 2018; this adoption rate is even higher among large companies worldwide [5]. In Taiwan, the Financial Supervisory Commission requested the listed companies with more than 10 billion NTD registered capitals to disclose their CSR status. The number of publicly listed companies filing CSR reports was merely 212 in 2013, which grew to 417 and 515 in 2018 and 2019, respectively [6]. Obviously, many listed companies and investors have recognized the value of CSR, and this tendency is gaining momentum.

Once a company takes formal action regarding CSR, it should follow guidance to prepare its report. The CSR report requires a certificate from a third party (e.g., an accounting or a consulting firm). Several organizations are in competition to set up guidance, but the ESG Principle (Environment, Social, and Governance) [7] from the UN might be the most prevailing one. The ESG Principle urges corporations to invest resources for sustainable developments in the three categories mentioned above, plus a synthetic one.

In practice, the joint force by the Coalition for Environmentally Responsible Economics (CERES) from the U.S. and the United Nations Environment Program (UNEP) from the UN, launched a project to promote the reporting system for sustainability in 1997. This project turned into a nonprofit organization: the Global Reporting Initiative (GRI) in 2002. Ever since, GRI has been devoted to promoting universal standards of sustainability reporting. The GRI has proposed several evolving reporting standards for CSR [8], which have been adopted by many listed companies.

Although many corporations recognize the value of CSR, its associated costs are considerable. Companies have to yield their short-term profitability to satisfy the associated CSR expenses. Why are business leaders, shareholders, and even potential investors keen to embrace CSR? The primary reason might be to strengthen a company's sustainability and long-term business value. In financial markets, the UN-backed Principles for Responsible Investment (PRI) have caused a significant impact, embraced by influential institutional investors [9]. Those PRI capitals are inclined to invest in companies that adopt the ESG Principle and have superior performances with respect to CSR. The incentives and benefits for businesses of embracing CSR are tangible.

Despite the favorable consequences of CSR, there are several limitations for corporations in devising CSR models in practice. Take the predominant ESG Principle, for instance, which echoes the UN's 17 sustainable development goals (SDGs), and includes around 169 indicators [10]. Among the 17 goals, some are at the national level (e.g., Goal One, No Poverty); but still, there are over 90 indicators that a company should address under its guidance. The complexity of its modeling is manifest. Additionally, some indicators (criteria) are interrelated with one another; the convoluted relationship among the criteria might impede businesses in establishing an adequate CSR evaluation model.

Furthermore, information asymmetry would be an issue, while a CSR evaluation model would be too complicated for the management team or stakeholders to comprehend. The term "information asymmetry" is taken from the renowned agency theory [11]. In financial research, agency theory presumes that shareholders are less informed compared with the management team or business executives. Previous research [12] has suggested that CSR performance is capable of mitigating information asymmetry. Nevertheless, too much heterogeneous information might blur its focus.

Take the two leading information technology (IT) companies' CSR reports as an example; the CSR reports from the Taiwan Semiconductor Manufacturing Company (TSMC, code: 2330) and Delta Group (code: 2308) were both over 150 pages in 2018 [6]. Their lengthy reports included numerous GRI indicators, but most of the figures lacked a common ground with which to make a cross-company comparison. Additionally, the relative importance of each indicator in evaluating CSR performance is unclear. A significant improvement in one indicator might be inferior to minor progress in another 
one. These issues not only exacerbate the information asymmetry problem, they also make it difficult for a company to identify its weakness priorities when planning systematic improvements.

To resolve the issues mentioned above, the multiple criteria decision-making (MCDM) or multi-criteria decision aid (MCDA) approaches would be adequate one. The MCDM approach hinges upon domain experts' knowledge and experience in modeling; it can retrieve crucial criteria to form a succinct and transparent decision model [13]. Additionally, the relative importance of each indicator (criterion) of a CSR model may not be the same in different industries. The MCDM approach has sufficient flexibility to yield various CSR evaluation models for different sectors based on the same ESG Principle with different criteria. Therefore, this study attempts to propose a hybrid MCDM approach, for the purpose of constructing a concise and transparent CSR evaluation model. The research goals are threefold: (1) provide a refined CSR model to mitigate the information asymmetry problem, (2) apply the obtained model to compare the CSR performance of different companies within the same industry, and (3) support a company to plan for systematic improvements.

To illustrate the refined CSR model, this study adopts the IT manufacturing industry of Taiwan as an empirical case. Within the global IT supply chain, Taiwan's manufacturers play an important role in many subsectors, such as in the semiconductor industry. Those IT manufacturers are crucial to the success of technology advancements, and their operations are located not only in Taiwan but also in other regions (e.g., Asia, the North America, and Europe). Their global influence is substantial.

In the empirical case study, we will compare the CSR performance of several world-class IT manufacturing companies. Additionally, we will suggest ways of leveraging the analytics from the refined CSR model to identify improvement priorities. The remaining sections are as follows. The literature review of CSR is presented in Section 2, and Section 3 explains the proposed hybrid MCDM model. Section 4 takes the IT manufacturing sector of Taiwan as an empirical case study and discusses the findings, and Section 5 concludes this study.

\section{Literature Review}

This section begins by introducing the background and financial impacts of CSR (Section 2.1). Section 2.2 discusses the critical role of information asymmetry in CSR. Finally, the related MCDM research methods are briefly discussed in Section 2.3.

\subsection{The Evolution of Corporate Social Responsibility}

The concept of CSR has a long and evolving history. In the past, mainstream financial studies concurred that a corporate should maximize the wealth of its shareholders as its primary goal. Although most financial studies agreed with this perspective, nevertheless, several studies have emphasized the social aspect of corporations [14-18] since the 1950s, and the debate is still controversial [19]. Since then, several international organizations inaugurated guidance and working groups to pursue in this direction; well-known examples include the multinational enterprise guidelines of the OECD (Organization for Economic Co-operation and Development) [20] and the UN Global Compact [21].

From the 1960s to 1990s, a growing number of empirical studies was published in the field of CSR. The necessity and plausible effects of CSR have been broadly examined [22,23]. Around the 1990s, several research themes related to CSR emerged; examples include environmental concerns [24], corporate social performance [25], and corporate governance [26]. During this period, the importance of CSR was widely examined and acknowledged. Several research themes have caused debates with respect to what should be highlighted or considered by businesses, aside from making profits. For instance, the thriving of modern industrialism has caused enormous pollution and wreaked irreversible harm on the earth. Environmental protection has become a critical concern for business operations.

Most people would agree that corporations should be responsible for controlling the environmental side-effects caused by their operations. Furthermore, certain research has revealed that the "going 
green" strategy may give rise to higher performance [27]. Thus, along with other themes, the UN concluded three crucial categories-Environment, Social, and Governance (ESG) [21]—to form its core CSR framework. Thus, the present study adopts the ESG Principle and the MCDM approach to devise a refined CSR evaluation model.

\subsubsection{Sustainability and Corporate Social Responsibility}

Aside from CSR, a broader and more impactful topic — sustainability—has attracted the UN's attention since the 1990s. The UN upholds the concept of "sustainability" at multiple levels, ranging from the national to the corporate level. The first summit related to sustainability was held in 1992, and led the UN's members to sign a formal agenda. As climate change and economic crises led to considerable suffering for the public, the UN attempted to align crucial goals for its members. In 2014, the UN announced 17 Sustainability Development Goals (SDGs), and it introduced several amendments in 2016 [10].

The present study regards the concept of sustainability to include CSR, which covers not only corporations but also nonprofit organizations (NGOs) and nations. Thus, a partial set of the 17 SDGs are the goals for corporations to pursue in CSR, excluding those for NGOs and nations. Thus, the present study leverages the knowledge from domain experts, to discern the SDGs that are associated with the corporate level. Under the ESG Principle, we may adopt the corporate-related SDGs as sustainable goals for CSR modeling. We illustrate this concept in Figure 1.

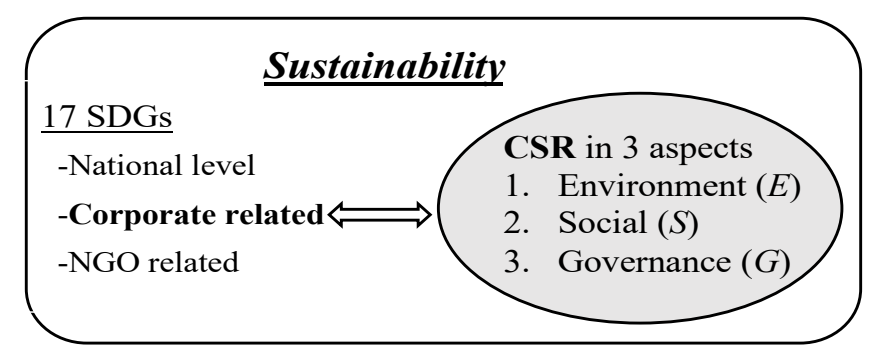

Figure 1. Conceptual relationships among sustainability, SDGs, and CSR.

Although the UN members reached a consensus on the 17SDGs, adequate indicators for monitoring progress - with consistency and comparability—are still required. These indicators should be capable of measuring the progress of each SDG, the associated indicators for which required much debate and effort on the part of experts to identify $[28,29]$. In the present study, we distill the critical indicators associated with the CSR-related SDGs. This two-step criteria reduction, from 17 SDGs to CSR-related SDGs and their associated critical indicators, is one of the major contributions of this study. We will report and illustrate the details in Section 4.

\subsubsection{Principles for Responsible Investment}

From the public's perspective, it is intuitive for companies to pursue CSR performance. However, if companies lack financial incentives to align their interests with the public, the actions for attaining higher CSR performance might not be sustainable. To bridge the gap, the UN brought the idea of PRI to the New York Stock Exchange in 2006. The evolving version comprises the ESG-related principles [30]; its main goal is to spur financial institutions to incorporate CSR into their investment decisions and post-management activities.

In PRI, the essential role of ESG is reiterated. PRI advocates that institutional investors allocate their capital to businesses that are devoted to the sustainability of the evolving ecosystem [31,32]. By doing so, PRI may serve as a driving force from the financial market. As more institutional investors embrace PRI and gain significant clout for their portfolios, capital markets will reward those businesses with superior CSR performance in the long run. 


\subsection{Information Asymmetry}

The renowned agency theory, proposed by Jenson and Meckling [33], indicates the potential interest of conflicts between agents and their stakeholders. In business, this often refers to the relationship between a management team and its shareholders. A management team might delude or mislead its shareholders, and information asymmetry often exacerbates the agency problem. Take the German-based fintech company Wirecard's recent financial deception for instance; it was revealed that $\$ 2$ billion was missing on its balance sheet [34] in June 2020. The Wirecard scandal is a typical example of information asymmetry.

Since a management team usually has more information than its shareholders, reducing this information gap would be a challenge. One of the promising approaches is to achieve higher CSR performance. Previous research suggests that corporate governance (a crucial aspect of CSR) has a negative relation with information asymmetry [35]. The higher the CSR performance, the lower the information asymmetry problem.

There are at least two plausible ways in which CSR may contribute to reducing information asymmetry. The first one is the disclosure of CSR reports, which have to be certified by a third party. A formal CSR report has to follow global standards, such as the widely adopted GRI series [8]. GRI has multiple developing versions; they all follow the ESG framework for pursuing sustainable goals [10]. In a CSR report, the CSR activities of a company are communicated based on its self-defined sustainability goals. The corporation has to report not only qualitative activities but also quantitative statistics—audited by an external independent organization-with respect to its annual progress on CSR.

The second cause might be the requested governance aspect of CSR. Corporate governance has various measures for evaluating the operations of a company to see if they are aligned with shareholders' interests [36]. Superior governance implies that a management team inclines to treat its shareholders fairly by offering transparent information. For instance, in financial markets, the Taiwan Stock Exchange (TWSE) devised a corporate governance evaluation system (CGES) [6] in 2014, and "Increasing information transparency" is one of its key dimensions for assessing publicly listed stocks' performance with respect to corporate governance. The influence of corporate governance on information transparency is evident.

\subsection{Multiple Criteria Decision-Making Methods for Performance Evaluation}

As discussed in Section 2.2, most CSR reports follow the prevailing GRI standards. Nevertheless, each corporation has to select its own sustainability goals in CSR to execute their action plans and organize the associated reports. It is difficult to compare the CSR performance of different companies without a common ground. To bridge this gap, the present study adopts the ESG Principle (as a framework) and proposes a hybrid MCDM approach to form a refined CSR evaluation model.

MCDM methods have been applied in various fields, from engineering to business [37], owing to their scientific approach when simultaneously considering multiple criteria. For instance, previous research has applied MCDM methods to evaluating practical problems as follows: (1) vendor evaluation problem [38], (2) corporate governance [36], (3) risk management in construction projects [39], third-party logistics provider evaluation [40], and (4) construction supplier selection [41].

Since there are various MCDM methods, we only discuss the most relevant methods to this study. A typical MCDM evaluation model comprises two parts: (1) obtain the weight of each indicator to form an evaluation system; and (2) assess the performance of each company on each criterion.

In the first part, MCDM methods' key value is due to the bounded rationality of humans; this idea was proposed by the Nobel Laureate H.A. Simon [42]. The bounded rationality theory presumes that a $\mathrm{DM}(\mathrm{s})$ has limited capability to make a decision by considering multiple factors (e.g., more than seven or eight factors) simultaneously. To resolve this problem, MCDM researchers proposed a prevailing pairwise comparison approach. 
The pairwise comparison approach requires DMs to judge the relative importance of two factors at a time. Then, different methods may adopt a series of pairwise comparisons to derive an overall weighting system. Among those pairwise comparison methods, the renowned Analytic Hierarchy Processes (AHP) and Analytic Network Processes (ANP) [43] might be the most broadly adopted MCDM methods [44]. The term "hierarchy" here refers to the general framework of a two-layer MCDM model, from dimensions to the associated criteria. In a hierarchical model, a dimension indicates an aspect, and the associated criteria are usually more explicit and measurable.

Though the ANP method has gained significant influence in decision science, its assumption of equal weight for dimensions might not be applicable in all circumstances. Therefore, the decision-making trial and evaluation laboratory (DEMATEL) technique [45] was incorporated into the concept of ANP, in order to yield the DEMATEL-based ANP (DANP) weighting method [46]. Not only can the weight of each dimension be identified, the DEMATEL technique can also clarify the cause-effect relationship among dimensions, which can help identify the root cause of an underperforming dimension.

The second part addresses performance assessment techniques. In some circumstances, it might be difficult to precisely assess an alternative's performance on each criterion. The conventional approach uses the Likert scale (e.g., from 1 to 5 points) or 100 as the full score, and experts or DMs should assign a crisp figure on each criterion for an alternative. However, experts or DMs might encounter obstacles to providing a precise score during an assessment. Therefore, in MCDM research, the soft computing assessment is gaining prevalence [47].

Among the various soft computing techniques, the fuzzy set theory extended technique [48] might be the most commonly adopted one. The classical triangular membership function can support experts in denoting their sematic opinions—such as "Bad" or "Good"—intuitively. As a result, both the crisp and fuzzy approach will be carried out for a comparison in this research.

\section{Methodology and Research Model}

The present study aims to provide a refined CSR evaluation model, based on the ESG Principle. As discussed in Section 2, the UN's sustainable goals have more than 160 indicators (criteria), and it is unrealistic to construct a CSR performance evaluation using all of those indicators. Thus, the present study takes a two-step approach: (1) use the Delphi method to extract the essential indicators (criteria); and (2) construct a hybrid MCDM evaluation model. The research's conceptual flow is illustrated in Figure 2, and it comprises four parts: (1) identify crucial indicators, (2) form a hybrid MCDM model, (3) performance assessment and aggregation, and (4) CSR applications.

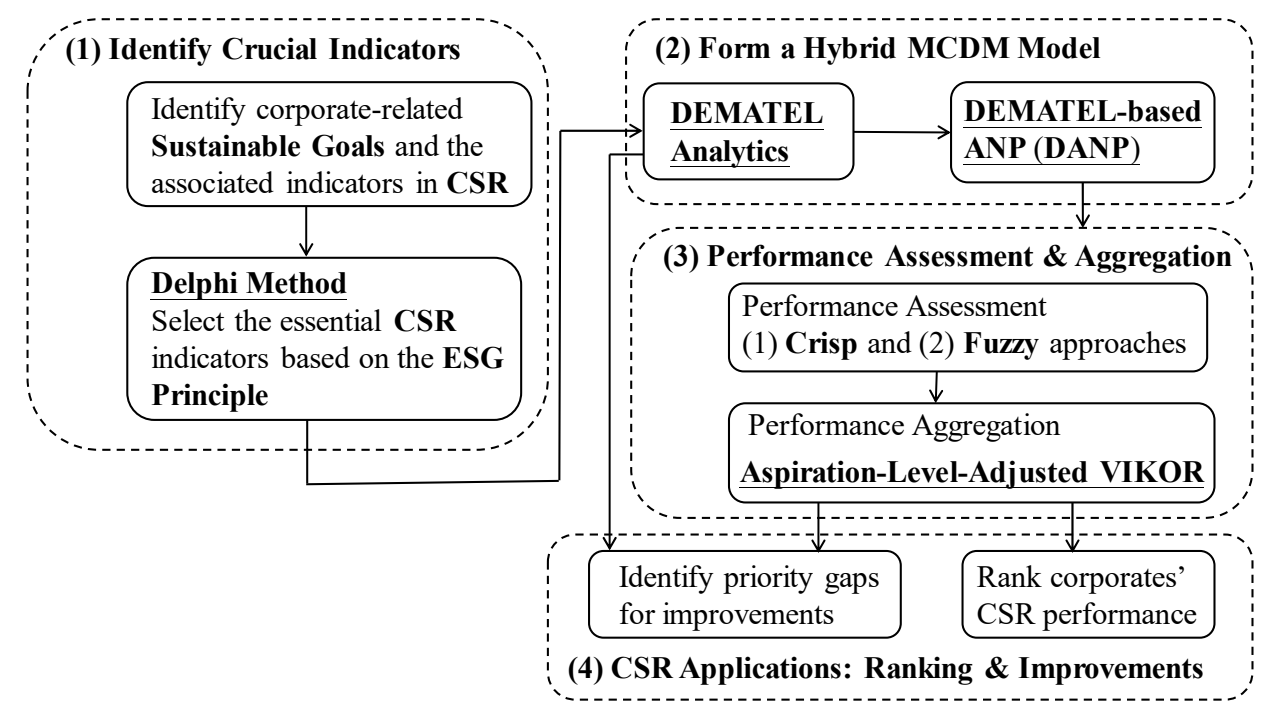

Figure 2. Research flow diagram of the hybrid MCDM approach. 


\subsection{Delphi Method}

The origin of the Delphi method can be traced back to the second world war. The U.S. government asked the Rand company to devise a consensus-reaching method from multiple experts with diverse backgrounds: the Delphi method [49]. Though there are various ways to adopt the Delphi method, Linstone and Turoff [50] described the essence of its characteristics: the Delphi method can be regarded as a communication process. It allows a group of experts to deal with a complex problem through structured communications. In addition, it usually takes more than one round to reach a consensus.

Among various approaches, the present study takes the threshold-setting one. Participants provide their opinions on the alternatives (i.e., SDG-related indicators, here), to grade the importance or relevance of the alternatives. If an alternative's averaged score is lower than a pre-assigned threshold, it will be removed. The average score of each alternative will be provided for the reference of participants in the next round, and each round may have different threshold values. Participants may change their opinions after referring to the result from the previous round. Once an acceptable consensus is obtained, the survey (communication) process may stop. More details about the Delphi method can be found in $[50,51]$.

Here, the function of the Delphi method is to extract the essential CSR assessment criteria to form a hybrid MCDM model. It consists of two stages (shown in Figure 3): (1) identify the corporation-related sustainable goals on the basis of the ESG Principle; and (2) extract the critical indicators for each dimension.

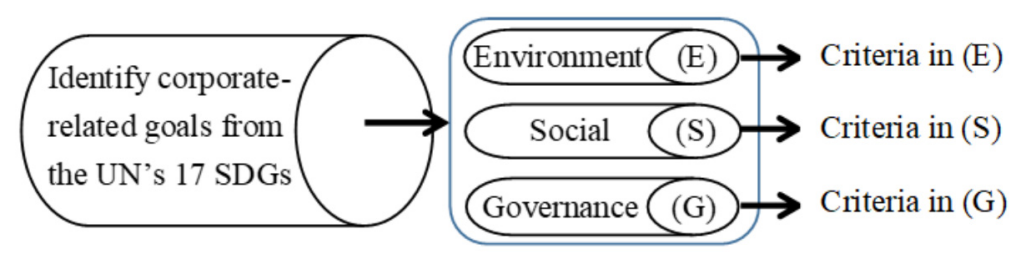

Figure 3. Use the Delphi method to identify criteria for the CSR model.

As discussed in Section 2, there are 169 indicators related to the 17 SDGs. Here, the three aspects Environment (E), Social (S), and Governance (G) are regarded as the three dimensions of the CSR model. The Delphi method hinges upon domain experts' knowledge-following the ESG Principle—to identify the critical indicators (criteria) of each dimension. The Delphi method has been broadly adopted in social sciences, and we manage to collect opinions from experts in three fields: (1) industry, (2) academic, and (3) CSR-related institutions. The invited experts all have more than 15 years' experience related to this topic. The details will be reported in Section 4 .

\subsection{DEMATEL and DEMATEL-Based ANP Influential Weighting System}

The DEMATEL technique is one of the early attempts that is capable of modeling the interdependence among variables (criteria). It focuses on resolving complicated social problems. It takes the following steps to implement the DEMATEL technique [45].

Step 1: Organize an initial influence matrix $A$.

The DEMATEL technique assumes that all factors (criteria) of a model are interdependent. To gauge the influential relationship among the criteria, it begins with collecting opinions from domain experts to form an initial influence matrix. Assume that there are $n$ criteria, each expert has to express their opinions such as "What is the influence of criterion $i$ on criterion $j(1 \leq i, j \leq n)$ ?" The influence 
score ranges from "0 (No Influence)" to " 4 (Very High Influence)" in a DEMATEL questionnaire. The average score of criterion $i$ on $j$ will be located in $A$ as in Equation (1).

$$
A=\left[\begin{array}{ccccc}
a_{11} & \cdots & a_{1 j} & \cdots & a_{1 n} \\
\vdots & \ddots & \vdots & \ddots & \vdots \\
a_{i 1} & \cdots & a_{i j} & \cdots & a_{i n} \\
\vdots & \ddots & \vdots & \ddots & \vdots \\
a_{n 1} & \cdots & a_{n j} & \cdots & a_{n n}
\end{array}\right]_{n \times n}, \text { for } 1<i, j \leq n
$$

Step 2: Transform $A$ into a normalized matrix $D$.

To normalize $A$, we should calculate the number $\mu$ in Equation (2). The normalized matrix $N$ can be obtained by: $D=\mu \times A$.

$$
\mu=\max \left\{\max _{i} \sum_{j=1}^{n} a_{i j}, \max _{j} \sum_{i=1}^{n} a_{i j}\right\}, i, j \in\{1,2, \cdots, n\} .
$$

Step 3: Derive the total influence relation matrix $T$.

The normalized matrix $\boldsymbol{N}$ can sum up the increasing power of $\boldsymbol{D}$ to obtain the total influence relation matrix $T\left(T=D+D^{2}+\ldots+D^{\infty}\right)$. This process is also termed the ripple effect, where $T$ can be shown as: $\boldsymbol{T}_{n \times n}=\boldsymbol{D} \times(\boldsymbol{I}-\boldsymbol{D})^{-1}=\left[t_{i j}\right]_{n \times n}$. Equation (3) explains the reason:

$$
\boldsymbol{T}_{n \times n}=\boldsymbol{T}=\boldsymbol{D}+\boldsymbol{D}^{2}+\ldots+\boldsymbol{D}^{w}=\boldsymbol{D}\left(\boldsymbol{I}-\boldsymbol{D}^{w}\right)(\boldsymbol{I}-\boldsymbol{D})^{-1} .
$$

While $w \rightarrow \infty, \boldsymbol{D}^{w} \cong[0]_{n \times n}$ and $\left(\boldsymbol{I}-\boldsymbol{D}^{w}\right)=\boldsymbol{I}$. Thus, the total influence relation matrix $\boldsymbol{T}$ can be obtained (also termed as $T_{C}^{D}$ ), where $p$ is the number of its dimensions and $n$ is the number of total criteria (for $p<n$ ); it is indicated as in Equation (4):

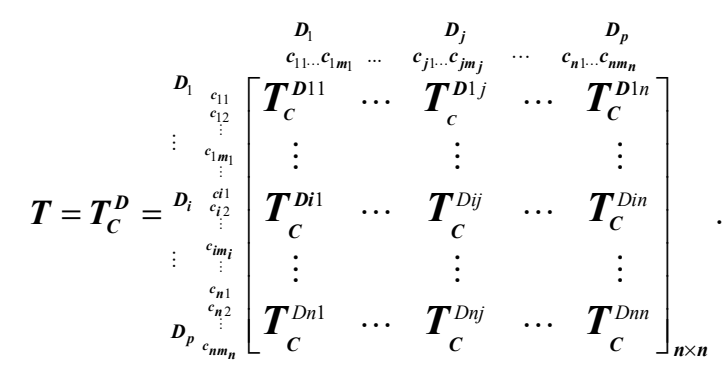

Step 4: Calculate the dimensional influence matrix.

After obtaining the total influence relation matrix $T$, all the criteria within the same dimension should be located in the same block as a sub-matrix $T_{S}^{D k l}(1<k, l<p<n$ and $k, l \in R)$. Assuming that there are $p(1<p<n$ and $p \in R)$ dimensions of $\boldsymbol{T}$, the total dimensional influence matrix can be denoted as in Equation (5):

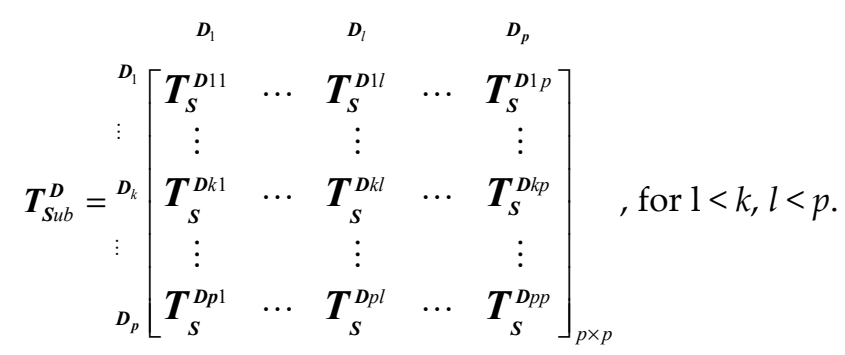


Each sub-matrix in $T_{\text {Sub }}^{D}$ can be transformed into a figure by averaging all the elements in it (e.g., transform sub-matrix $T_{S}^{D k l}$ into $t_{k l}^{D}$ ). Then, the sum of each row and each column can form two vectors, as in Equation (6) and the transformed $T^{D}$ is denoted as in Equation (7):

$$
\begin{gathered}
\mathrm{R}^{D}=\left[\sum_{l=1}^{p} t_{1 l}^{D} \cdots \sum_{l=1}^{p} t_{p l}^{D}\right]_{p \times 1}, \mathrm{D}^{D}=\left[\sum_{k=1}^{p} t_{k 1}^{D} \cdots \sum_{k=1}^{p} t_{k p}^{D}\right]_{1 \times p}, \text { and } \\
\boldsymbol{T}^{D}=\left[\begin{array}{ccccc}
t_{11}^{D} & \cdots & t_{1 l}^{D} & \cdots & t_{1 p}^{D} \\
\vdots & \ddots & \vdots & \ddots & \vdots \\
t_{k 1}^{D} & \cdots & t_{k l}^{D} & \cdots & t_{k p}^{D} \\
\vdots & \ddots & \vdots & \ddots & \vdots \\
t_{p 1}^{D} & \cdots & t_{p l}^{D} & \cdots & t_{p p}^{D}
\end{array}\right]_{p \times p}, \text { for } 1<k, l<p .
\end{gathered}
$$

Here, $\mathrm{R}^{D}+\mathrm{D}^{D}$ and $\mathrm{R}^{D}-\mathrm{D}^{D}$ can from a dimensional cause-effect diagram. This diagram may serve as a guidance to devise CSR improvement plans.

Step 5: Calculate the DEMATEL-adjusted ANP weights.

In $T^{\mathrm{D}}$, each element of a row should be normalized by dividing the sum of all figures of a row (e.g., $\sum_{l=1}^{p} t_{k l}^{D}$ for the k-th row). The normalized $\boldsymbol{T}^{D}$ (i.e., ${ }^{N} \boldsymbol{T}^{D}$ ) is shown in Equation (8), and the transpose of $T_{C}^{D}$ is regarded as an initial super-matrix of the ANP method (i.e., $\left(T_{C}^{D}\right)^{\prime}=W^{\text {ini }}$ ).

$$
{ }^{\mathrm{N}} \boldsymbol{T}^{D}=\left[\begin{array}{ccc}
t_{11}^{D} / \sum_{k=1}^{p} t_{1 k}^{D} & \cdots & t_{1 p}^{D} / \sum_{k=1}^{p} t_{1 k}^{D} \\
\vdots & \ddots & \vdots \\
t_{p 1}^{D} / \sum_{k=1}^{p} t_{p k}^{D} & \cdots & t_{p p}^{D} / \sum_{k=1}^{p} t_{p k}^{D}
\end{array}\right]_{p \times p}
$$

The DANP weights of a hierarchical decision model—with $p$ dimensions and $n$ criteria—can be obtained by multiplying ${ }^{N} T^{D}$ with the transpose of $T_{C}^{D}$, to get the DEMATEL-adjusted super-matrix: $\boldsymbol{W}_{\mathrm{DEM}}^{\mathrm{ini}}={ }^{\mathrm{N}} \boldsymbol{T}^{D} \times\left(\boldsymbol{T}_{\mathrm{C}}^{D}\right)^{\prime}={ }^{\mathrm{N}} \boldsymbol{T}^{D} \times \boldsymbol{W}^{\text {ini }}$. The DEMATEL-adjusted ANP weights can be reached by multiplying $W_{\text {DEM }}^{\text {ini }}$ with itself $\varphi(\varphi \in R)$ times until the super-matrix reaches a stable state, to become the final DANP matrix. The obtained relative influence of each criterion should be normalized to sum up to $100 \%$.

\subsection{Aspiration-Level-Adjusted VIKOR Aggregator}

To construct an MCDM model to assist a ranking decision comprises three parts: (1) gain the relative influence or importance of each criterion, (2) assess a group of alternatives' performance on each criterion, and (3) aggregate each alternative's overall performance. This concept is also illustrated in Figure 2. In MCDM research, to aggregate the performance gap of each alternative on each criterion and identify the one with the minimal overall performance gap is another prevailing approach, such as the classical VIKOR method.

The concept of the aspiration-level-adjust VIKOR [13,52] attempts to overcome the potential ranking-reversal issue of the original VIKOR method, which sets the aspiration level of each criterion as the full score. This method begins with a predefined Lp-matric. Assume that there are $n$ criteria and $q$ alternatives of a model, and the score of each alternative ranges from " 1 (worst)" to "10 (best)." The influential weight of each criterion is $w_{j}($ for $j=1, \ldots, n)$, obtained from the DANP method. Then, 
the Lp-matric denotes the aggregated performance gap of each alternative on each criterion, shown in Equation (9):

$$
L p^{V I K O R}=\left\{\sum_{j=1}^{n}\left[w_{j}\left(\left|p_{j}^{\Delta}-p_{k j}\right|\right) /\left(p_{j}^{\Delta}-p_{j}^{\perp}\right)\right]^{\Theta}\right\}^{\frac{1}{\Theta}} .
$$

In Equation (9), $1 \leq \Theta<\infty$ and $j=1, \ldots, n ; p_{j}^{\Delta}$ and $p_{j}^{\perp}$ denote the aspired to and the worst performance level of criterion $j$, respectively. Three indices should be calculated to aggregate the performance gaps of each alternative, namely $S, R$, and $Q$. We can get $S_{k}$ by setting $\Theta=1$ in Equation (9) for alternative $k$, and $\Theta \simeq \infty$ to obtained $R_{k}$. Based on previous work [13], $S_{k}$ denotes the weighted average of performance gaps and $R_{k}$ the highest weighted gap of alternative $k$. In addition, $Q$ is the compromised index by assigning different weights on $S$ and $R$ (shown in Equation (10)), which may be applied as a sensitivity analysis with different values of $v(0 \leq v \leq 1)$.

$$
Q_{k}=v \times\left[\frac{S_{k}-S^{\Delta}}{S^{\nabla}-S^{\Delta}}\right]+(1-v) \times\left[\frac{R_{k}-R^{\Delta}}{R^{\nabla}-R^{\Delta}}\right]
$$

In Equation (10), $S^{\nabla}$ and $R^{\nabla}$ denote the highest performance gaps for the two indices, and $S^{\Delta}=$ $R^{\Delta}=0$ the $R^{\Delta}$ lowest performance gaps, respectively. In the aspiration-level-adjusted approach, the four values are set as: $S^{\nabla}=R^{\nabla}=1$ and $S^{\Delta}=R^{\Delta}=0$. Those settings imply that the aspiration level is zero performance gap on all criteria. Index $Q$ decides the final ranking, the lower the better. The approach of combining DANP and VIKOR to form hybrid models has achieved promising results in different fields. Examples are the evaluations of e-businesses [53], glamor stock [54], and medical device investment project [55]. The theoretical foundation paves a solid way to the modeling for this study.

\section{Empirical Case and Discussions}

This section adopts the proposed hybrid MCDM approach to forming a CSR evaluation model. The IT manufacturing sector of Taiwan is an indispensable part of the global supply chain. From the world-leading semiconductor industry to those brand-name 3C (computer, communication, and consumer electronics) appliances, this sector is the cornerstone of economic developments of Taiwan.

In the early stage, this sector boomed at the cost of environment pollution. However, the growing awareness of environmental protection and the balance between local employment and rising domestic labor costs also baffled those giant IT companies. To be a responsible business for the society, CSR might be the right goal to pursue. The empirical case study not only applied the model to ranking four listed companies but also proposed guidance of how an IT manufacturing company may gain insights to forming its CSR improvement plans.

\subsection{Data}

This study invited 10 domain experts to take part in the research. In the first stage, seven experts joined the survey (i.e., Delphi method). In the second stage, 10 experts filled in the DEMATEL questionnaires for deriving the DANP influential weights of the CSR evaluation model. The 10 domain experts had CSR-related knowledge either from their work or research, and they all had over 20 years' experience in the IT industry, academia, or NGOs.

The evaluation of CSR is a complicated process that involves environment, social, and governance aspects. Therefore, there is no universal agreement on how many indicators should be included. Additionally, owing to the complexity of practical problems, MCDM-method-based research usually involved limited experts during the survey. Therefore, with reference to previous research $[41,56,57]$, the present study invited seven experienced experts to take part in the Delphi survey.

Finally, five experts provided their assessments regarding how the example companies performed on the CSR model's criteria in 2018, both in crisp and fuzzy evaluations. The evaluation details are 
presented in Section 4.3. After several rounds of discussion, the experts all agreed with the ESG framework that this study adopted. They also shared their opinions regarding how this approach might help corporations focus limited resources on pursuing superior CSR performance. The experts' summary is presented in Table 1.

Table 1. Summary of experts in each stage.

\begin{tabular}{ccccc}
\hline & \multicolumn{4}{c}{ (Numbers of Participated Experts in Different Stages) } \\
\cline { 2 - 5 } & Industry & Academia & Institution & Total \\
\hline Delphi survey & 4 & 3 & 0 & 7 \\
\hline DEMATEL \& DANP & 6 & 3 & 1 & 10 \\
\hline Performance evaluation & 3 & 1 & 1 & 5 \\
\hline Job titles & $\begin{array}{c}\text { CSR Executive, CSR Vice } \\
\text { President, Senior Manager }\end{array}$ & $\begin{array}{c}\text { Associate Professor, } \\
\text { Full Professor }\end{array}$ & $\begin{array}{c}\text { Secretary General (Taiwan } \\
\text { Academia of Corporate } \\
\text { Sustainability) }\end{array}$ \\
\hline
\end{tabular}

One thing that should be highlighted, here, is that the experts were invited to join these surveys based on their availability, and the experts who were serving in academia had either IT or financial industry working experience. Four renowned IT companies of Taiwan were chosen for the final stage., The numbers of criteria in each dimension after two rounds of the Delphi survey are summarized in Table 2, and the concise definitions of those criteria are presented in Table 3.

Table 2. Numbers of indicators of each dimension.

\begin{tabular}{cccc}
\hline Dimensions & Initial Stage & First Round & Second Round \\
\hline Environmental (E) & 39 & 8 & 4 \\
Social (S) & 23 & 13 & 2 \\
Governance (G) & 30 & 21 & 6 \\
Total & 93 & 42 & 12 \\
\hline
\end{tabular}

We identified those corporate-related sustainable goals and their associated indicators (see Figure 3), and those indicators were categorized into three dimensions, respectively. The experts were asked to give a grade to each indicator, ranging from 0 (Not Important) to 10 (Extremely Important). With reference to previous MCDM empirical studies [36,41,46,54,55], this study set a target of including 8 to 15 criteria. We began with a lower threshold (i.e., at least higher than 7.0) in the first round and identified 42 indicators. To meet the target, we raised the threshold to 8.0 in the second round and obtained 12 indicators in the three dimensions. This outcome is in line with the target, and this study finalized the model with the 12 criteria.

To examine the proposed approach, this study referred to reports from the prominent CommonWealth Magazine [58], which has hosted an annual contest for Taiwan incorporated companies since 2007. Based on the invited experts' recommendations and the accessibility of the companies' CSR-related open data, this study selected four publicly listed companies in Taiwan from the IT manufacturing sector; their backgrounds are presented in Table 4. The four companies all have operations outside Taiwan. Among them, the two semiconductor-related corporations (i.e., TSMC: Hsinchu, Taiwan and ASE Technology Holding: Kaohsiung, Taiwan) contribute to countless new IT electronics (e.g., 5G stations and smartphones), which are highly influential to the global IT industry.

One thing that should be mentioned: the experts' recommendations are crucial here. Since we construct a hybrid decision model with the 12 extracted criteria, we have to collect the relevant data (include their CSR reports, official website information, and annual financial statements) regarding those criteria and request the experts to make assessments accordingly. This process is interactive and time-consuming. 
There are no standard materials that are similar to financial figures (such as earnings per share) here; we had to leverage the experts' in-depth understanding of the selected companies to collect the relevant materials. The experts' experience and knowledge were essential for this CSR model. In other words, the experts absorbed the relevant information for the 12 criteria from the four companies and transformed them into comparable performance ratings. We will report the evaluation results in Section 4.3.

Table 3. Brief definitions of the dimensions and criteria.

\begin{tabular}{|c|c|c|}
\hline Dimensions & Criteria & Definitions \\
\hline \multirow{4}{*}{$\begin{array}{l}\text { Environment } \\
\qquad\left(D_{1}\right)\end{array}$} & $\begin{array}{l}\text { Energy saving and intelligent } \\
\text { operation management }\left(C_{1}\right)\end{array}$ & $\begin{array}{l}\text { Implement green manufacturing, and reduce energy } \\
\text { consumption in the overall business operations. }\end{array}$ \\
\hline & Water resource management $\left(C_{2}\right)$ & $\begin{array}{l}\text { Implement water resource management with ISO 14001, } \\
\text { promote water and electricity saving, air pollution prevention } \\
\text { and waste reduction. }\end{array}$ \\
\hline & Waste management $\left(C_{3}\right)$ & $\begin{array}{l}\text { Carry out environmental impact assessments and management, } \\
\text { including carcinogens, radiation, ozone layer destruction, } \\
\text { toxicity, acidification, and petrochemical fuels. }\end{array}$ \\
\hline & Air pollution prevention $\left(C_{4}\right)$ & $\begin{array}{l}\text { Air pollution prevention system must comply with Taiwan's air } \\
\text { pollution control and emission standards, and overseas factories } \\
\text { also comply with local emission regulations. }\end{array}$ \\
\hline \multirow{2}{*}{$\begin{array}{c}\text { Social } \\
\left(D_{2}\right)\end{array}$} & $\begin{array}{l}\text { Labor rights and employee } \\
\text { relations }\left(C_{5}\right)\end{array}$ & $\begin{array}{l}\text { Provide a safe and healthy working environment and training in } \\
\text { accordance with labor laws, increase work safety, and eliminate } \\
\text { illegality and discrimination. }\end{array}$ \\
\hline & Healthy and safe workplace $\left(C_{6}\right)$ & $\begin{array}{l}\text { Deepen health concept, care for employees and family members, } \\
\text { conduct regular factory fire inspections and tests, and control } \\
\text { risks through on-site investigations and drills. }\end{array}$ \\
\hline \multirow{6}{*}{$\begin{array}{l}\text { Governance } \\
\qquad\left(D_{3}\right)\end{array}$} & Quality shareholder feedbacks $\left(C_{7}\right)$ & $\begin{array}{l}\text { Hold board meetings at least once a quarter to review business } \\
\text { performance and discuss important issues. }\end{array}$ \\
\hline & $\begin{array}{l}\text { Communication with stakeholders } \\
\qquad\left(C_{8}\right)\end{array}$ & $\begin{array}{l}\text { Prepare CSR report according to the GRI reporting guidelines } \\
\text { and communicate with stakeholders through multiple channels. }\end{array}$ \\
\hline & Management with integrity $\left(C_{9}\right)$ & $\begin{array}{l}\text { Formulate integrity code of conduct to perform annual risk } \\
\text { assessments and keep reporting channels open. }\end{array}$ \\
\hline & Risk and crisis management $\left(C_{10}\right)$ & $\begin{array}{l}\text { Regularly assess emerging risks and trends in the industry, } \\
\text { manage risks, and do financial and operational crisis control. }\end{array}$ \\
\hline & $\begin{array}{l}\text { Disclose transparent CSR status } \\
\qquad\left(C_{11}\right)\end{array}$ & $\begin{array}{l}\text { Report the annual results of "Corporate Social Responsibility } \\
\text { Committee" to the board of directors transparently. }\end{array}$ \\
\hline & $\begin{array}{l}\text { Control and ensure information } \\
\text { security }\left(C_{12}\right)\end{array}$ & $\begin{array}{l}\text { Ensure the safety of information security and manufacturing } \\
\text { process, and prevent information security vulnerability with } \\
\text { early detection. }\end{array}$ \\
\hline
\end{tabular}

Table 4. Summary of the four companies' information in 2019.

\begin{tabular}{|c|c|c|c|c|}
\hline Companies & ${ }^{\mathrm{a}}$ Codes & Main Business & Employees & Share Capital (NTD) \\
\hline TSMC (T) & 2330 & $\begin{array}{l}\text { Manufacturing semiconductor } \\
\text { integrated circuits }\end{array}$ & 48,752 & $259.3 \mathrm{~B}$ \\
\hline $\begin{array}{c}\text { Micro-Star } \\
\text { International }(M)\end{array}$ & 2377 & $\begin{array}{l}\text { Brand name computer hardware and } \\
\text { software design and manufacturing }\end{array}$ & 2760 & $8.4 \mathrm{~B}$ \\
\hline $\begin{array}{l}\text { ASE Technology } \\
\text { Holding }(A)\end{array}$ & 3711 & $\begin{array}{l}\text { Semiconductor manufacturing } \\
\text { services in assembly and test }\end{array}$ & 93,891 & $43.4 \mathrm{~B}$ \\
\hline Coretronic $(C)$ & 5371 & $\begin{array}{l}\text { Manufacturing LCD, digital projector, } \\
\text { and LCD backlight related products }\end{array}$ & 16,026 & $4.3 \mathrm{~B}$ \\
\hline
\end{tabular}

${ }^{a}$ Those are the listing codes of the companies in the Taiwan Stock Exchange (TWSE).

\subsection{DEMATEL Analytics and DANP Influential Weights}

The initial influence matrix $A$ and the total influence relation matrix $\boldsymbol{T}$ are in Tables 5 and 6 (shown as $T_{\text {Sub }}^{D}$ ). After averaging all the elements of each submatrix in Table 6, the dimensional matrix $T^{D}$ was obtained and shown in Table 7 with $\mathrm{R}_{l}^{D}$ and $\mathrm{D}_{k}^{D}$ (for $l, k=\{1,2,3\}$ ). 
Table 5. Initial influence matrix $A$.

\begin{tabular}{|c|c|c|c|c|c|c|c|c|c|c|c|c|}
\hline Criteria & $C_{1}$ & $C_{2}$ & $C_{3}$ & $C_{4}$ & $C_{5}$ & $C_{6}$ & $C_{7}$ & $C_{8}$ & $C_{9}$ & $C_{10}$ & $C_{11}$ & $C_{12}$ \\
\hline$C_{2}$ & 1.30 & 0.00 & 2.10 & 2.50 & 1.50 & 1.10 & 1.10 & 1.90 & 1.00 & 1.40 & 1.90 & 0.80 \\
\hline$C_{4}$ & 1.30 & 2.60 & 2.60 & 0.00 & 2.30 & 1.30 & 1.50 & 2.20 & 1.30 & 2.00 & 2.00 & 0.40 \\
\hline$C_{5}$ & 1.70 & 1.90 & 2.20 & 2.30 & 0.00 & 2.60 & 1.20 & 1.70 & 1.60 & 0.90 & 2.00 & 0.60 \\
\hline$C_{6}$ & 0.60 & 1.40 & 1.40 & 1.40 & 3.00 & 0.00 & 0.60 & 1.00 & 0.70 & 1.30 & 1.20 & 0.40 \\
\hline$C_{9}$ & 1.20 & 1.30 & 1.40 & 1.70 & 2.20 & 0.90 & 1.70 & 1.40 & 0.00 & 1.60 & 2.00 & 1.80 \\
\hline$C_{10}$ & 1.00 & 1.40 & 1.90 & 2.20 & 1.20 & 1.00 & 2.40 & 1.40 & 1.80 & 0.00 & 2.40 & 2.20 \\
\hline$C_{11}$ & 1.60 & 2.60 & 2.60 & 2.70 & 2.30 & 1.90 & 2.40 & 2.60 & 2.10 & 2.20 & 0.00 & 1.80 \\
\hline$C_{12}$ & 1.10 & 1.00 & 0.90 & 0.80 & 1.00 & 0.50 & 1.30 & 0.80 & 1.80 & 2.00 & 1.80 & 0.00 \\
\hline
\end{tabular}

Table 6. Total influence relation matrix $T^{\mathrm{a}}$.

\begin{tabular}{ccccccccccccc}
\hline Criteria & $\boldsymbol{C}_{\mathbf{1}}$ & $\boldsymbol{C}_{\mathbf{2}}$ & $\boldsymbol{C}_{\mathbf{3}}$ & $\boldsymbol{C}_{\mathbf{4}}$ & $\boldsymbol{C}_{\mathbf{5}}$ & $\boldsymbol{C}_{\mathbf{6}}$ & $\boldsymbol{C}_{\mathbf{7}}$ & $\boldsymbol{C}_{\mathbf{8}}$ & $\boldsymbol{C}_{\mathbf{9}}$ & $\boldsymbol{C}_{\mathbf{1 0}}$ & $\boldsymbol{C}_{\mathbf{1 1}}$ & $\boldsymbol{C}_{\mathbf{1 2}}$ \\
\hline $\boldsymbol{C}_{\mathbf{1}}$ & 0.08 & 0.16 & 0.14 & 0.16 & 0.16 & 0.10 & 0.11 & 0.14 & 0.12 & 0.13 & 0.15 & 0.12 \\
$\boldsymbol{C}_{\mathbf{2}}$ & 0.17 & 0.17 & 0.25 & 0.28 & 0.24 & 0.17 & 0.18 & 0.23 & 0.18 & 0.21 & 0.25 & 0.14 \\
$\boldsymbol{C}_{\mathbf{3}}$ & 0.17 & 0.27 & 0.18 & 0.29 & 0.27 & 0.18 & 0.17 & 0.24 & 0.18 & 0.21 & 0.25 & 0.13 \\
$\boldsymbol{C}_{\mathbf{4}}$ & 0.19 & 0.29 & 0.30 & 0.22 & 0.29 & 0.20 & 0.21 & 0.27 & 0.21 & 0.26 & 0.28 & 0.14 \\
$\boldsymbol{C}_{\mathbf{5}}$ & 0.19 & 0.26 & 0.27 & 0.29 & 0.20 & 0.23 & 0.19 & 0.24 & 0.21 & 0.20 & 0.27 & 0.14 \\
$\boldsymbol{C}_{\mathbf{6}}$ & 0.12 & 0.19 & 0.19 & 0.20 & 0.25 & 0.10 & 0.13 & 0.16 & 0.14 & 0.17 & 0.19 & 0.10 \\
$\boldsymbol{C}_{\mathbf{7}}$ & 0.17 & 0.24 & 0.25 & 0.28 & 0.26 & 0.18 & 0.16 & 0.24 & 0.23 & 0.29 & 0.30 & 0.18 \\
$\boldsymbol{C}_{\mathbf{8}}$ & 0.20 & 0.29 & 0.30 & 0.33 & 0.31 & 0.22 & 0.23 & 0.20 & 0.25 & 0.27 & 0.32 & 0.19 \\
$\boldsymbol{C}_{\mathbf{9}}$ & 0.17 & 0.22 & 0.23 & 0.26 & 0.26 & 0.16 & 0.20 & 0.21 & 0.14 & 0.22 & 0.26 & 0.18 \\
$\boldsymbol{C}_{\mathbf{1 0}}$ & 0.17 & 0.24 & 0.26 & 0.29 & 0.24 & 0.18 & 0.24 & 0.23 & 0.22 & 0.18 & 0.29 & 0.21 \\
$\boldsymbol{C}_{\mathbf{1 1}}$ & 0.23 & 0.34 & 0.34 & 0.37 & 0.34 & 0.25 & 0.28 & 0.32 & 0.27 & 0.31 & 0.26 & 0.22 \\
$\boldsymbol{C}_{\mathbf{1 2}}$ & 0.13 & 0.17 & 0.17 & 0.18 & 0.18 & 0.12 & 0.16 & 0.15 & 0.18 & 0.20 & 0.21 & 0.09 \\
\hline \multicolumn{8}{c}{ a Refer Equation (5), $\boldsymbol{T}$ comprises $9(3 \times 3)$ submatrices. }
\end{tabular}

Table 7. Dimensional influence matrix.

\begin{tabular}{ccccc}
\hline Dimensions & $\boldsymbol{D}_{\mathbf{1}}$ & $\boldsymbol{D}_{\mathbf{2}}$ & $\boldsymbol{D}_{\mathbf{3}}$ & $\mathbf{R}^{\boldsymbol{D}}$ \\
\hline $\boldsymbol{D}_{\mathbf{1}}$ & 0.21 & 0.20 & 0.19 & 0.60 \\
$\boldsymbol{D}_{\mathbf{2}}$ & 0.21 & 0.20 & 0.18 & 0.59 \\
$\boldsymbol{D}_{\mathbf{3}}$ & 0.24 & 0.23 & 0.22 & 0.69 \\
\hline $\mathbf{D}^{\boldsymbol{D}}$ & 0.66 & 0.62 & 0.59 & \\
\hline
\end{tabular}

As stated in Step $4, \mathrm{R}^{D}+\mathrm{D}^{D}$ and $\mathrm{R}^{D}-\mathrm{D}^{D}$ can identify the directional influence relationship among the three dimensions. The in-depth cause-effect relationship within a dimension can be analyzed by similar procedures. We summarize and report the analytics in Table 8 and Figure 4 . The findings suggest that Governance $\left(D_{3}\right)$ is the source of the other two dimensions: Environment $\left(D_{1}\right)$ and Social $\left(D_{2}\right)$. This echoes the importance of corporate governance, which might be a key reason why the Taiwan Stock Exchange (TWSE) compels listed companies to disclose their corporate governance reports earnestly. With reference to Step $5, T^{D}$ was normalized to multiply with the transpose of the total influence matrix, and the DEMATEL-adjusted initial super-matrix $W_{\text {DEM }}^{\text {ini }}$ was obtained, as shown in Table 9. After multiplying with itself several times, the converged final influential weights are in the next subsection. 


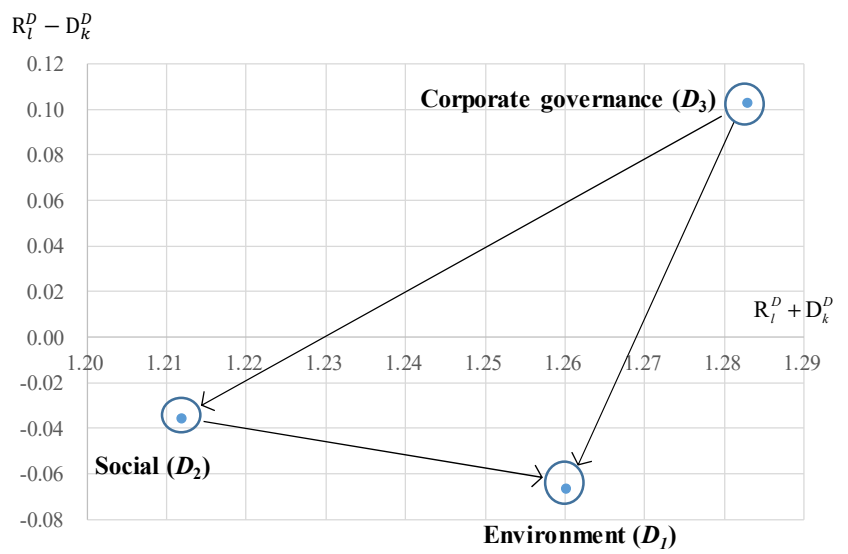

Figure 4. Cause-effect relationship among the three dimensions.

Table 8. Directional influence relationship analysis.

\begin{tabular}{cccccc}
\hline Dimensions & $\boldsymbol{R}_{\boldsymbol{l}}^{D}$ & $\boldsymbol{D}_{\boldsymbol{k}}^{\boldsymbol{D}}$ & $\boldsymbol{R}_{\boldsymbol{l}}^{\boldsymbol{D}}+\boldsymbol{D}_{\boldsymbol{k}}^{\boldsymbol{D}}$ & $\boldsymbol{R}_{\boldsymbol{l}}^{\boldsymbol{D}}-\boldsymbol{D}_{\boldsymbol{k}}^{\boldsymbol{D}}$ & Cause/Effect \\
\hline Environment $\left(D_{1}\right)$ & 0.60 & 0.66 & 1.26 & -0.07 & Effect \\
Social $\left(D_{2}\right)$ & 0.59 & 0.62 & 1.21 & -0.04 & Effect \\
Governance $\left(D_{3}\right)$ & 0.69 & 0.59 & 1.28 & 0.10 & Cause \\
\hline
\end{tabular}

Table 9. DEMATEL-adjusted initial super-matrix.

\begin{tabular}{ccccccccccccc}
\hline Criteria & $\boldsymbol{C}_{\mathbf{1}}$ & $\boldsymbol{C}_{\mathbf{2}}$ & $\boldsymbol{C}_{\mathbf{3}}$ & $\boldsymbol{C}_{\mathbf{4}}$ & $\boldsymbol{C}_{\mathbf{5}}$ & $\boldsymbol{C}_{\mathbf{6}}$ & $\boldsymbol{C}_{\mathbf{7}}$ & $\boldsymbol{C}_{\mathbf{8}}$ & $\boldsymbol{C}_{\mathbf{9}}$ & $\boldsymbol{C}_{\mathbf{1 0}}$ & $\boldsymbol{C}_{\mathbf{1 1}}$ & $\boldsymbol{C}_{\mathbf{1 2}}$ \\
\hline $\boldsymbol{C}_{\mathbf{1}}$ & 0.05 & 0.07 & 0.06 & 0.06 & 0.07 & 0.06 & 0.06 & 0.06 & 0.07 & 0.06 & 0.06 & 0.07 \\
$\boldsymbol{C}_{\mathbf{2}}$ & 0.10 & 0.07 & 0.10 & 0.10 & 0.09 & 0.10 & 0.09 & 0.09 & 0.09 & 0.09 & 0.09 & 0.09 \\
$\boldsymbol{C}_{\mathbf{3}}$ & 0.09 & 0.10 & 0.07 & 0.10 & 0.10 & 0.10 & 0.09 & 0.09 & 0.09 & 0.10 & 0.09 & 0.09 \\
$\boldsymbol{C}_{\mathbf{4}}$ & 0.10 & 0.11 & 0.11 & 0.08 & 0.10 & 0.11 & 0.10 & 0.10 & 0.10 & 0.11 & 0.10 & 0.10 \\
$\boldsymbol{C}_{\mathbf{5}}$ & 0.20 & 0.20 & 0.20 & 0.20 & 0.15 & 0.24 & 0.19 & 0.19 & 0.20 & 0.19 & 0.19 & 0.20 \\
$\boldsymbol{C}_{\mathbf{6}}$ & 0.13 & 0.14 & 0.13 & 0.14 & 0.18 & 0.10 & 0.13 & 0.14 & 0.12 & 0.14 & 0.14 & 0.13 \\
$\boldsymbol{C}_{\mathbf{7}}$ & 0.05 & 0.05 & 0.05 & 0.05 & 0.05 & 0.04 & 0.04 & 0.05 & 0.05 & 0.06 & 0.05 & 0.05 \\
$\boldsymbol{C}_{\mathbf{8}}$ & 0.06 & 0.06 & 0.06 & 0.06 & 0.06 & 0.06 & 0.06 & 0.04 & 0.06 & 0.05 & 0.06 & 0.05 \\
$\boldsymbol{C}_{\mathbf{9}}$ & 0.05 & 0.05 & 0.05 & 0.05 & 0.05 & 0.05 & 0.05 & 0.06 & 0.04 & 0.05 & 0.05 & 0.06 \\
$\boldsymbol{C}_{\mathbf{1 0}}$ & 0.05 & 0.06 & 0.06 & 0.06 & 0.05 & 0.06 & 0.07 & 0.06 & 0.06 & 0.04 & 0.06 & 0.07 \\
$\boldsymbol{C}_{\mathbf{1 1}}$ & 0.06 & 0.07 & 0.07 & 0.07 & 0.07 & 0.06 & 0.07 & 0.07 & 0.07 & 0.07 & 0.05 & 0.07 \\
$\boldsymbol{C}_{\mathbf{1 2}}$ & 0.05 & 0.04 & 0.03 & 0.03 & 0.03 & 0.03 & 0.04 & 0.04 & 0.05 & 0.05 & 0.04 & 0.03 \\
\hline
\end{tabular}

\subsection{CSR Performance Evaluation}

To access the CSR performance of the four companies, we collected their self-disclosed CSR reports in 2018. Additionally, some additional information was retrieved as supplementary information for the experts to provide their grading. As mentioned earlier, both crisp (from 1 to 10) and fuzzy evaluations (i.e., Bad (B), Moderate (M), and Good (G)) were conducted. The five experts' fuzzy triangular membership parameters for the three levels are presented in Table 10.

Table 10. Five experts' fuzzy sematic evaluation parameters.

\begin{tabular}{cccccc}
\hline & Expert 1 & Expert 2 & Expert 3 & Expert 4 & Expert 5 \\
\hline Good $(\mathrm{G})$ & $\mathrm{a}(7,10,10)$ & $(6.5,10,10)$ & $(7,10,10)$ & $(7,10,10)$ & $(6,10,10)$ \\
Moderate (M) & $(3,5,7)$ & $(3,5,7)$ & $(4,5,7)$ & $(4,5,7)$ & $(3,5,7)$ \\
Bad (B) & $(0,0,3)$ & $(0,0,3.5)$ & $(0,0,4)$ & $(0,0,4)$ & $(0,0,4)$ \\
\hline
\end{tabular}

${ }^{a}$ These are the parameters of the fuzzy triangular membership function.

Overall, this study applied the combinations of two assessment approaches (crisp and fuzzy) and two performance aggregation methods (simple additive weight (SAW) and aspiration-level-adjusted VIKOR). First, the CSR performance ranking result of two assessment approaches by using the SAW is 
shown in Table 11. Second, we replaced the SAW with the aspiration-level-adjusted VIKOR method with a sensitivity analysis, reported in Table 12.

Table 11. CSR performance evaluation by using SAW aggregation.

\begin{tabular}{cccccccccc}
\hline \multirow{2}{*}{ Criteria } & \multirow{2}{*}{$\begin{array}{c}\text { DANP } \\
\text { Weights }\end{array}$} & \multicolumn{3}{c}{ a Crisp Evaluations (0 to 10) } & \multicolumn{3}{c}{ b Fuzzy Evaluations (Bad to Good) } \\
\cline { 3 - 9 } & & $\boldsymbol{T}$ & $\boldsymbol{M}$ & $\boldsymbol{A}$ & $\boldsymbol{C}$ & $\boldsymbol{T}$ & $\boldsymbol{M}$ & $\boldsymbol{A}$ & $\boldsymbol{C}$ \\
\hline$C_{1}$ & $6.40 \%$ & 9.50 & 5.80 & 8.20 & 8.10 & 8.90 & 7.37 & 8.17 & 8.90 \\
$C_{2}$ & $9.25 \%$ & 8.90 & 4.60 & 8.20 & 8.20 & 8.90 & 3.27 & 8.90 & 8.90 \\
$C_{3}$ & $9.42 \%$ & 8.70 & 5.80 & 7.80 & 8.70 & 8.90 & 7.37 & 8.90 & 8.17 \\
$C_{4}$ & $10.26 \%$ & 8.20 & 5.70 & 7.20 & 7.60 & 7.30 & 6.63 & 6.57 & 7.37 \\
$C_{5}$ & $19.42 \%$ & 8.80 & 6.30 & 7.60 & 8.10 & 8.90 & 7.37 & 8.17 & 8.17 \\
$C_{6}$ & $13.87 \%$ & 8.90 & 6.00 & 7.80 & 7.20 & 8.90 & 7.37 & 6.57 & 6.57 \\
$C_{7}$ & $4.77 \%$ & 9.30 & 7.50 & 8.20 & 7.50 & 8.17 & 7.37 & 8.17 & 6.57 \\
$C_{8}$ & $5.73 \%$ & 8.00 & 6.80 & 7.70 & 7.40 & 7.30 & 7.37 & 8.17 & 8.17 \\
$C_{9}$ & $4.92 \%$ & 8.90 & 6.90 & 8.60 & 7.00 & 8.90 & 7.43 & 8.17 & 7.43 \\
$C_{10}$ & $5.60 \%$ & 8.70 & 6.70 & 7.50 & 7.50 & 8.90 & 7.37 & 7.30 & 8.17 \\
$C_{11}$ & $6.56 \%$ & 8.60 & 7.00 & 7.70 & 6.30 & 8.90 & 6.63 & 8.17 & 6.57 \\
$C_{12}$ & $3.81 \%$ & 7.70 & 7.00 & 7.60 & 7.40 & 7.30 & 7.37 & 8.17 & 8.17 \\
\hline & Final result & 8.43 & 5.90 & 7.49 & 7.41 & 8.55 & 6.87 & 7.87 & 7.76 \\
& (Ranking) & $(1)$ & $(4)$ & $(2)$ & $(3)$ & $(1)$ & $(4)$ & $(2)$ & $(3)$ \\
\hline
\end{tabular}

${ }^{a}$ The crisp performance scores are the arithmetic means of the five experts. ${ }^{b}$ The fuzzy evaluations were transformed from sematic expressions (i.e., Good, Moderate, and Bad; refer to Table 10) into those defuzzified average performance scores.

Table 12. Aspiration-level-adjusted VIKOR aggregation with fuzzy evaluations.

\begin{tabular}{cccccc}
\hline \multirow{2}{*}{ Criteria } & \multirow{2}{*}{$\begin{array}{c}\text { DANP } \\
\text { Weights }\end{array}$} & \multicolumn{4}{c}{ Four Example Companies } \\
\cline { 3 - 6 } & & $\boldsymbol{T}$ & $\boldsymbol{M}$ & $\boldsymbol{A}$ & $\boldsymbol{C}$ \\
\hline & & ${ }^{\mathrm{a}}$ w-PGap & w-PGap & w-PGap & w-PGap \\
$C_{1}$ & $6.40 \%$ & $0.70 \%$ & $1.68 \%$ & $1.17 \%$ & $0.70 \%$ \\
$C_{2}$ & $9.25 \%$ & $1.02 \%$ & $\mathbf{6 . 2 3} \%$ & $1.02 \%$ & $1.02 \%$ \\
$C_{3}$ & $9.42 \%$ & $1.04 \%$ & $2.48 \%$ & $1.04 \%$ & $1.72 \%$ \\
$C_{4}$ & $10.26 \%$ & $\mathbf{2 . 7 7} \%$ & $3.46 \%$ & $3.52 \%$ & $2.70 \%$ \\
$C_{5}$ & $19.42 \%$ & $2.14 \%$ & $5.11 \%$ & $3.55 \%$ & $3.55 \%$ \\
$C_{6}$ & $13.87 \%$ & $1.53 \%$ & $3.65 \%$ & $4.76 \%$ & $4.76 \%$ \\
$C_{7}$ & $4.77 \%$ & $0.87 \%$ & $1.25 \%$ & $0.87 \%$ & $1.64 \%$ \\
$C_{8}$ & $5.73 \%$ & $1.55 \%$ & $1.51 \%$ & $1.05 \%$ & $1.05 \%$ \\
$C_{9}$ & $4.92 \%$ & $0.54 \%$ & $1.26 \%$ & $0.90 \%$ & $1.26 \%$ \\
$C_{10}$ & $5.60 \%$ & $0.62 \%$ & $1.47 \%$ & $1.51 \%$ & $1.02 \%$ \\
$C_{11}$ & $6.56 \%$ & $0.72 \%$ & $2.21 \%$ & $1.20 \%$ & $2.25 \%$ \\
$C_{12}$ & $3.81 \%$ & $1.03 \%$ & $1.00 \%$ & $0.70 \%$ & $0.70 \%$ \\
& $S$ & $14.52 \%$ & $31.31 \%$ & $21.29 \%$ & $22.38 \%$ \\
& $R$ & $2.77 \%$ & $6.23 \%$ & $4.76 \%$ & $4.76 \%$ \\
& $Q(v=0.95)$ & $13.93 \%$ & $30.06 \%$ & $20.46 \%$ & $21.50 \%$ \\
& $Q(v=0.90)$ & $13.34 \%$ & $28.80 \%$ & $19.63 \%$ & $20.61 \%$ \\
& $Q(v=0.85)$ & $12.76 \%$ & $27.55 \%$ & $18.81 \%$ & $19.73 \%$ \\
& $Q(v=0.80)$ & $12.17 \%$ & $26.29 \%$ & $17.98 \%$ & $18.85 \%$ \\
& $($ Ranking) & $(1)$ & $(4)$ & $(2)$ & $(3)$ \\
\hline
\end{tabular}

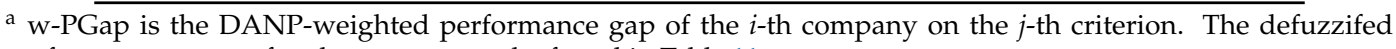
performance scores of each company can be found in Table 11.

In Table 12, the bold figures are the highest-weighted performance gap (w-PGap) of each company. The interesting finding is that the top- and bottom-ranked companies' priority issues are in the Environment $\left(D_{1}\right)$ dimension. From Table 8 and Figure 4 , it can be seen that both Governance $\left(D_{3}\right)$ and Social $\left(D_{2}\right)$ dimensions are sources of influence on this dimension. 
Additionally, the crisp evaluations indicate the same rankings with different values of $v$ (i.e., $T>A>C>M$ ). Thus, we only report the fuzzy evaluation-based VIKOR aggregation results in Table 12. All the experiments show consistent ranking, including the sensitivity test by using different values of $v$. We will discuss the ranking of this study with the CommonWealth Magazine's 2019 contest in Section 5.

\subsection{Systematic Improvement Guidance}

The key advantage of this hybrid MCDM approach is its potential to guide a company to pursue systematic and continuous improvements. As can be seen from Tables 11 and 12, even the top performing Company T (TSMC) did not reach the aspiration levels, 10 in the crisp and "Good (G)" in the fuzzy evaluation, for all the criteria. Here, we take the example of the third-ranked company (i.e., Company $C$ ); its top priority was $C_{6}$ (Healthy and safe workplace).

Though there are various ways to conduct improvement planning, this study proposes a systematic approach based on the findings of the hybrid CSR model. The presumption is that limited resources should be allocated to the priority gap that will lead to the highest marginal improvement of overall CSR performance. Therefore, the suggested steps are as follows:

(1) Prioritize a company's weighted CSR performance gap;

(2) Clarify the sources of influence of the top priority;

(3) Devise improvement plans based on the available resources that not only emphasize the critical priority but also the sources of influences.

In this case, the top weighted performance gap is $C_{6}$ (Healthy and safe workplace), which is in the Social dimension $\left(D_{2}\right)$. We also know that the source dimension is $D_{3}$ (Governance). Then, we may delve into the cause-effect within the two dimensions (i.e., the cause-effect relationship among the criteria). The DEMATEL calculations follow similar steps to those in Section 3.2, and the cause-effect analytics are presented in Table 13.

Table 13. DEMATEL-analytics of two dimensions.

\begin{tabular}{|c|c|c|c|c|c|c|c|c|c|}
\hline & \multicolumn{4}{|c|}{ Social $\left(D_{2}\right)$} & & \multicolumn{4}{|c|}{ Governance $\left(D_{3}\right)$} \\
\hline & $\mathrm{R} c$ & $\mathrm{Dc}$ & $\mathrm{R} c+\mathrm{D} c$ & $\mathrm{R} c-\mathrm{D} c$ & & $\mathrm{R} c$ & $\mathrm{D} c$ & $\mathrm{R} c+\mathrm{D} c$ & $\mathrm{R} c-\mathrm{D} c$ \\
\hline$C_{5}$ & 2.69 & 3.01 & 5.69 & -0.32 & $C_{7}$ & 2.77 & 2.26 & 5.03 & 0.52 \\
\hline \multirow[t]{5}{*}{$C_{6}$} & 1.94 & 2.10 & 4.04 & -0.16 & $C_{8}$ & 3.11 & 2.62 & 5.73 & 0.49 \\
\hline & & & & & $C_{9}$ & 2.52 & 2.31 & 4.83 & 0.20 \\
\hline & & & & & $C_{10}$ & 2.76 & 2.65 & 5.41 & 0.11 \\
\hline & & & & & $C_{11}$ & 3.53 & 3.05 & 6.58 & 0.48 \\
\hline & & & & & $C_{12}$ & 1.93 & 1.84 & 3.78 & 0.09 \\
\hline
\end{tabular}

In Table $13, C_{5}$ 's value of " $\mathrm{R} c-\mathrm{Dc}$ " is lower than $C_{6}{ }^{\prime} \mathrm{s}$, which implies that $C_{6}$ is the cause. Therefore, we turn our attention to the cause-effect relationship among the criteria of $D_{3}$. Additionally, from Table 12, the top priority performance gap (2.25\%, w-PGap) of Company $C$ is $C_{11}$ (Disclose transparent CSR status). The DEMATEL analytic reveals that only $C_{7}$ (Quality shareholder feedbacks) and $C_{8}$ (Communication with stakeholders) have higher values of $\mathrm{R} c-\mathrm{D} c$ than $C_{11}$, which suggests that improving the underperforming $C_{11}$ will depend on more effective stakeholder communication.

Based on the analytics, Company $C$ may thus devise action plans accordingly, to improve its overall CSR performance. For instance, it may conduct constructive dialogues with its key stakeholders, such as their employees, board members, supplies, and main customers, to align their vision towards the company's long-term sustainability. This systematic and insightful improvement approach is the major contribution of this hybrid approach. 


\section{Concluding Remarks}

Overall, this study contributes to retrieving domain experts' knowledge under the prevailing ESG Principle, using a scientific approach; it is positioned as an empirical study with practical insights. The present study paves the way for giant IT manufacturers to pursue superior CSR performance in a transparent and systematic manner. Nowadays, the value of CSR is widely recognized; however, the UN's CSR reporting protocols (i.e., the GRI series) are not capable of delivering a common basis for performance comparison. Additionally, the GRI protocols lack a practical tool for companies to identify their CSR priorities, in order to plan for systematic improvements. The proposed hybrid model bridges this gap.

In Section 4, all the ranking outcomes are consistent. In fact, the CommonWealth Magazine's 2019 CSR contest (the most prominent one in Taiwan) reveals a similar outcome: $T>C>M$. Since the CommonWealth Magazine has a rule that only companies with at least three consecutive profit records are invited, the recent merger deal of Company $A$ failed to satisfy this requirement. The main body of Company $A$ is the biggest provider of semiconductor manufacturing services in assembly and testing; it merged with another listed company (Siliconware Precision Industries Co: Hsinchu, Taiwan, the second largest player in the same sector) and relisted as a new holding company in 2018. Thus, it was not invited by the CommonWealth Magazine in 2019. The contest evaluated the CSR performance of the invited companies in 2018 (the same as in the present study), and reported the results in 2019. Its results suggest the validity of this approach. Thus, the major findings of this research are as follows:

(1) identify the essential criteria for forming a concise CSR evaluation model,

(2) clarify the source dimension-Governance $\left(D_{3}\right)$ —of the CSR model,

(3) rank the CSR performance of four IT manufactures in Taiwan in 2018 and find a consistent result by various experiments,

(4) suggest how to adopt the findings to devise improvement plans for Company $C$ with a priority.

Aside from the findings, this study still has several limitations. First, to form a concise model, the extracted criteria might not cover the full spectrum of CSR. Second, we only examined the four corporations that the experts suggested. Even when we conducted a sensitivity analysis and found consistent ranking, the validity of the evaluation outcome hinges upon the knowledge of the experts. Last, we presume the correctness of the self-disclosed CSR information from the four companies. Future research may collaborate with target companies to gain more accurate and in-depth understandings. Beyond the IT sector, there is a continuing need for an adequate CSR model for other businesses. The differences in each sector may lead to dissimilar emphases on the associated criteria. Future research may explore other sectors by adopting this approach.

Author Contributions: Conceptualization, Y.-L.W., K.-Y.S., and J.-Y.H.; methodology, K.-Y.S.; investigation, Y.-L.W. and J.-Y.H.; resources, P.L.; writing-original draft preparation, Y.-L.W. and K.-Y.S.; writing—review and editing, K.-Y.S.; supervision, P.L.; project administration, K.-Y.S.; funding acquisition, K.-Y.S. All authors have read and agreed to the published version of the manuscript.

Funding: This research was funded by the Ministry of Science and Technology of Taiwan (R.O.C.), grant number 107-2410-H-034-018-MY2. The APC was also funded by 107-2410-H-034-018-MY2.

Acknowledgments: The authors are grateful to the experts' efforts and time spent for this research. Without their supports, we will not be able to complete the modeling and performance evaluations.

Conflicts of Interest: The authors declare no conflict of interest.

\section{References}

1. Elkington, J. Partnerships from cannibals with forks: The triple bottom line of 21st-century business. Environ. Qual. Manag. 1998, 8, 37-51. [CrossRef]

2. Govindan, K.; Khodaverdi, R.; Jafarian, A. A fuzzy multi criteria approach for measuring sustainability performance of a supplier based on triple bottom line approach. J. Clean. Prod. 2013, 47, 345-354. [CrossRef] 
3. Carroll, A.B.; Buchholtz, A.K. Business and Society: Ethics, Sustainability, and Stakeholder Management; Cengage Learning: Stamford, CT, USA, 2014.

4. Costa, R.; Menichini, T. A multidimensional approach for CSR assessment: The importance of the stakeholder perception. Expert Syst. Appl. 2013, 40, 150-161. [CrossRef]

5. Lukomnik, J. State of Integrated and Sustainability Reporting 2018; Harvard Law School Forum on Corporate Governance: Boston, MA, USA. Available online: https://corpgov.law.harvard.edu/2018/12/03/ (accessed on 29 December 2019).

6. Corporate Governance Center, TWSE. Available online: https://cgc.twse.com.tw/frontEN/index (accessed on 1 February 2020).

7. Rahman, S. Evaluation of definitions: Ten dimensions of corporate social responsibility. World Rev. Bus. Res. 2011, 1, 166-176.

8. GRI official website. Available online: https://www.globalreporting.org/Pages/default.aspx (accessed on 31 December 2019).

9. Dyck, A.; Lins, K.V.; Roth, L.; Wagner, H.F. Do institutional investors drive corporate social responsibility? International evidence. J. Financ. Econ. 2019, 131, 693-714. [CrossRef]

10. Sustainable Development Goals. UN Official Website. Available online: https://sustainabledevelopment.un. org/ (accessed on 30 January 2020).

11. Eisenhardt, K.M. Agency theory: An assessment and review. Acad. Manag. Rev. 1989, 14, 57-74. [CrossRef]

12. Cui, J.; Jo, H.; Na, H. Does corporate social responsibility affect information asymmetry? J. Bus. Ethics 2018, 148, 549-572. [CrossRef]

13. Tzeng, G.H.; Shen, K.Y. New Concepts and Trends of Hybrid. Multiple Criteria Decision Making; CRC Press: New York, NY, USA, 2017.

14. Eells, R. Social responsibility: Can business survive the challenge? Bus. Horizons 1959, 2, 33-41. [CrossRef]

15. Klick, M.T. The political economy of corporate social responsibility and community. Economics 1960, 3, 1-44.

16. Davis, K. Can business afford to ignore social responsibilities? Calif. Manag. Rev. 1960, 2, 70-76. [CrossRef]

17. Carroll, A.B. Corporate social responsibility: Evolution of a definitional construct. Bus. Soc. 1999, 38, $268-295$. [CrossRef]

18. Gilbert, D.U.; Rasche, A. Discourse ethics and social accountability: The ethics of SA 8000. Bus. Ethics Q. 2007, 17, 187-216. [CrossRef]

19. Nuryani, N.N.J.; Satrawan, D.P.R.; Gorda, A.A.N.O.S.; Martini, L.K.B. Influence of human capital, social capital, economic capital towards financial performance \& corporate social responsibility. Int. J. Soc. Sci. Humanit. 2018, 2, 65-76. [CrossRef]

20. OECD Official Website. Available online: https://www.oecd.org/corporate/mne/ (accessed on 31 December 2019).

21. UN Global Compact, Official Website. Available online: https://www.unglobalcompact.org (accessed on 31 December 2019).

22. Aupperle, K.E.; Carroll, A.B.; Hatfield, J.D. An empirical examination of the relationship between corporate social responsibility and profitability. Acad. Manag. J. 1985, 28, 446-463. [CrossRef]

23. Zahra, S.A.; LaTour, M.S. Corporate social responsibility and organizational effectiveness: A multivariate approach. J. Bus. Ethics 1987, 6, 459-467. [CrossRef]

24. Hussain, S.S. The ethics of 'going green': The corporate social responsibility debate. Bus. Strategy Environ. 1999, 8, 203-210. [CrossRef]

25. Wood, D.J. Corporate social performance revisited. Acad. Manag. Rev. 1991, 16, 691-718. [CrossRef]

26. Shleifer, A.; Vishny, R.W. A survey of corporate governance. J. Financ. 1997, 52, 737-783. [CrossRef]

27. Judge, W.Q.; Douglas, T.J. Performance implications of incorporating natural environmental issues into the strategic planning process: An empirical assessment. J. Manag. Stud. 1998, 35, 241-262. [CrossRef]

28. Stafford-Smith, M. UN sustainability goals need quantified targets. Nat. News 2014, 513, 281. [CrossRef]

29. Hák, T.; Janoušková, S.; Moldan, B. Sustainable Development Goals: A need for relevant indicators. Ecol. Indic. 2016, 60, 565-573. [CrossRef]

30. Principles for Responsible Investment (PRI), United Nations, Official website. Available online: https: //www.unpri.org/ (accessed on 30 January 2020).

31. Gond, J.P.; Piani, V. Enabling institutional investors' collective action: The role of the principles for responsible investment initiative. Bus. Soc. 2013, 52, 64-104. [CrossRef] 
32. Majoch, A.A.; Hoepner, A.G.; Hebb, T. Sources of stakeholder salience in the responsible investment movement: Why do investors sign the principles for responsible investment? J. Bus. Ethics 2017, 140, 723-741. [CrossRef]

33. Jenson, M.C.; Meckling, W.H. Theory of the firm: Managerial behavior, agency costs and ownership structure. J. Financ. Econ. 1976, 3, 305-360. [CrossRef]

34. Davies, P.J. Payments giant Wrecard's shares plunge on $\$ 2$ billion audit deception. Wall Street J. Available online: https://www.wsj.com/articles/payments-giant-wirecards-shares-plunge-on-2-billion-auditdeception-11592474551 (accessed on 19 June 2020).

35. Cormier, D.; Ledoux, M.J.; Magnan, M.; Aerts, W. Corporate governance and information asymmetry between managers and investors. Corp. Gov. Int. J. Bus. Soc. 2010, 10, 574-589. [CrossRef]

36. Huang, J.Y.; Shen, K.Y.; Shieh, J.C.; Tzeng, G.H. Strengthen financial holding companies' business sustainability by using a hybrid corporate governance evaluation model. Sustainability 2019, 11, 582. [CrossRef]

37. Shen, K.Y.; Zavadskas, E.K.; Tzeng, G.H. Updated discussions on 'Hybrid multiple criteria decision-making methods: A review of applications for sustainability issues. Econ. Res. Ekon. Istraž. 2018, 31, 1437-1452. [CrossRef]

38. Zavadskas, E.K.; Turskis, Z.; Kildienè, S. State of art surveys of overviews on MCDM/MADM methods. Technol. Econ. Dev. Econ. 2014, 20, 165-179. [CrossRef]

39. Chatterjee, K.; Zavadskas, E.K.; Tamošaitienè, J.; Adhikary, K.; Kar, S. A hybrid MCDM technique for risk management in construction projects. Symmetry 2018, 10, 46. [CrossRef]

40. Liu, Y.; Zhou, P.; Li, L.; Zhu, F. An interactive decision-making method for third-party logistics provider selection under hybrid multi-criteria. Symmetry 2020, 12, 729. [CrossRef]

41. Matić, B.; Jovanović, S.; Das, D.K.; Zavadskas, E.K.; Stević, Ž.; Sremac, S.; Marinković, M. A new hybrid MCDM model: Sustainable supplier selection in a construction company. Symmetry 2019, 11, 353. [CrossRef]

42. Simon, H.A. Bounded rationality in social science: Today and tomorrow. Mind Soc. 1991, 1, 25-39. [CrossRef]

43. Saaty, T.L. Decision making-The analytic hierarchy and network processes (AHP/ANP). J. Syst. Sci. Syst. Eng. 2005, 13, 1-35. [CrossRef]

44. Kou, G.; Ergu, D. AHP/ANP theory and its application in technological and economic development: The 90th anniversary of Thomas L. Saaty. Technol. Econ. Dev. Econ. 2016, 22, 649-650. [CrossRef]

45. Lee, H.S.; Tzeng, G.H.; Yeih, W.; Wang, Y.J.; Yang, S.C. Revised DEMATEL: Resolving the infeasibility of DEMATEL. Appl. Math. Model. 2013, 37, 6746-6757. [CrossRef]

46. Shen, K.Y.; Tzeng, G.H. Combining DRSA decision-rules with FCA-based DANP evaluation for financial performance improvements. Technol. Econ. Dev. Econ. 2015, 22, 685-714. [CrossRef]

47. Stojčić, M.; Zavadskas, E.K.; Pamučar, D.; Stević, Ž.; Mardani, A. Application of MCDM methods in sustainability engineering: A literature review 2008-2018. Symmetry 2019, 11, 350. [CrossRef]

48. Liao, H.; Mardani, A.; Zavadskas, E.K.; Bedregal, B. Editorial message: Special issue on fuzzy systems in intelligent systems and applications. Int. J. Fuzzy Syst. 2020, 22, 476. [CrossRef]

49. Okoli, C.; Pawlowski, S.D. The Delphi method as a research tool: An example, design considerations and applications. Inf. Manag. 2004, 42, 15-29. [CrossRef]

50. Linstone, H.A.; Turoff, M. (Eds.) The Delphi Method: Techniques and Applications; Addison-Wesley Publishing Company: Chicago, IL, US, 1975; ISBN 0201042932.

51. Flostrand, A.; Pitt, L.; Bridson, S. The Delphi technique in forecasting-A 42-year bibliographic analysis (1975-2017). Echnol. Forecast. Soc. Chang. 2020, 150, 119773. [CrossRef]

52. Opricovic, S.; Tzeng, G.H. Extended VIKOR method in comparison with outranking methods. Eur. J. Oper. Res. 2007, 178, 514-529. [CrossRef]

53. Chiu, W.Y.; Tzeng, G.H.; Li, H.L. A new hybrid MCDM model combining DANP with VIKOR to improve e-store business. Knowl. Based Syst. 2013, 37, 48-61. [CrossRef]

54. Shen, K.Y.; Yan, M.R.; Tzeng, G.H. Combining VIKOR-DANP model for glamor stock selection and stock performance improvement. Knowl. Based Syst. 2014, 58, 86-97. [CrossRef]

55. Huang, C.Y.; Hsieh, H.L.; Chen, H. Evaluating the investment projects of spinal medical device firms using the real option and DANP-mV based MCDM methods. Int. J. Environ. Res. Public Health 2020, 17, 3335. [CrossRef]

56. Huang, C.Y.; Shyu, J.Z.; Tzeng, G.H. Reconfiguring the innovation policy portfolios for Taiwan's SIP Mall industry. Technovation 2007, 27, 744-765. [CrossRef] 
57. Liou, J.J.; Tamošaitienè, J.; Zavadskas, E.K.; Tzeng, G.H. New hybrid COPRAS-G MADM Model for improving and selecting suppliers in green supply chain management. Int. J. Prod. Res. 2016, 54, 114-134. [CrossRef]

58. CommonWealth Magazine (Excellence in Corporate Social Responsibility) Official Website. Available online: https://topic.cw.com.tw/csr/report_EN.aspx (accessed on 28 February 2020). 